\title{
Article
}

\section{mmW Rotman Lens-Based Sensing: An Investigation Study}

\author{
Waleed T. Sethi ${ }^{1, *}$, Ahmed B. Ibrahim ${ }^{2} \mathbb{D}$, Khaled Issa ${ }^{3} \mathbb{D}$ and Saleh A. Alshebeili ${ }^{4}$ \\ 1 Faculty of Electrical Engineering, Ghulam Ishaq Khan Institute of Engineering Sciences and Technology, \\ Swabi 23640, Pakistan \\ 2 KACST-TIC in Radio Frequency and Photonics (RFTONICS), King Saud University, \\ Riyadh 11421, Saudi Arabia; ahahmed@ksu.edu.sa \\ 3 Laboratory of Electronics and Microelectronics, Department of Physics, Faculty of Sciences of Monastir, \\ University of Monastir, Monastir 5000, Tunisia; khaled.issa@yahoo.fr \\ 4 Electrical Engineering Department, King Saud University, Riyadh 11421, Saudi Arabia; dsaleh@ksu.edu.sa \\ * Correspondence: wsethi@giki.edu.pk
}

\section{check for}

updates

Citation: Sethi, W.T.; Ibrahim, A.B.; Issa, K.; Alshebeili, S.A. mmW Rotman Lens-Based Sensing: An Investigation Study. Sensors 2021, 21, 1163. https://doi.org/

$10.3390 /$ s21041163

Academic Editor: Serioja Ovidiu Tatu Received: 11 January 2021

Accepted: 3 February 2021

Published: 7 February 2021

Publisher's Note: MDPI stays neutral with regard to jurisdictional claims in published maps and institutional affiliations.

Copyright: (c) 2021 by the authors. Licensee MDPI, Basel, Switzerland. This article is an open access article distributed under the terms and conditions of the Creative Commons Attribution (CC BY) license (https:// creativecommons.org/licenses/by/ $4.0 /)$.

\begin{abstract}
A Rotman lens is a wideband true-time delay device. Due to its simplistic structure with wave/signal routing capabilities, it has been widely utilized as a beamforming device in numerous communication systems. Since the basic Rotman lens design incorporates multiple input, output, and dummy ports, in this study, and for the first time, we utilized a Rotman lens as a sensor. The main idea was to gather abundant information from available Rotman lens ports to obtain better sensing performance. The realized lens is optimized to work in the millimeter wave (mmW) band from 27 to $29 \mathrm{GHz}$ with a focus on a central frequency of $28 \mathrm{GHz}$. The design has a footprint of $140 \times 103 \times 0.8 \mathrm{~mm}^{3}$. The polarity correlator was used to characterize the material under investigation.
\end{abstract}

Keywords: $28 \mathrm{GHz}$; millimeter wave (mmW); Rotman lens; sensor

\section{Introduction}

Microwave/RF sensors have gained much attention in the research community compared to traditional wire-based and magnetic induction sensing due to their usage in minutely detecting and characterizing materials wirelessly [1]. Due to the success rate of these devices in sensing minute changes, the instrument and material characterization industry is working hard to improve the existing tools. The RF sensors are utilized in sensing tiny changes, whether at the molecular level, like sensing glucose solution concentration [2], or at the physical level, by assisting in the daily living healthcare of patients and healthy beings alike [3]. This is to fulfill the requirements for characterizing materials in the field of food processing monitoring, agricultural research, seismic detection, and chemical composition and biosensor applications. Characterizing a material is of crucial importance in understanding the scientific logic behind it and allowing oneself to further investigate the material or sample properties firsthand.

Numerous sensor designs have been realized that efficiently and precisely perform sensing tasks [4-6]. Some examples include the technology of split ring resonators, transmission lines, reflection-based resonators, dielectric resonators, substrate integrated waveguide technology, and resonant perturbation methods [7]. Some types of these sensors operate with a single port for analysis and others utilize two-port networks, based on system requirements. Nevertheless, each sensor performs well for specific frequency bands, selective physical properties of materials, and narrow applications defined by its own constraints. Furthermore, this group of microwave methods are dependent on the s-parameter behavior to detect and extract the properties of materials. The amount of change in frequency shifts of s-parameters and the E-field distributions on the sensor structure would reflect the accuracy and sensitivity of the sensor. 
A beamforming technique that offers simplicity in design, cost efficiency, ease of implementation, and wide scanning ability is offered by the Rotman lens, proposed in the year 1963 [8]. With its simple geometric design, the Rotman lens can easily steer beams in the desired direction, providing the same results as complex phase shifters [9]. Being a truetime delay device, it also offers a wide band characteristic as it is frequency independent. The design is widely appreciated in $\mathrm{mmW}$ band applications due to minimal surface and conduction losses [10,11].

In this study, and for the first time, we designed a basic Rotman lens and investigated its use as a sensor. The main idea was to take advantage of the wideband characteristics of the Rotman lens in order to gather abundant data captured from multiple ports for signal processing analysis. The focus was not on the beam steering capabilities of the Rotman lens but rather on sensing the changes in frequency responses of different materials over the entire spectrum band of interest to determine the parameter characterizing a given material. The proposed Rotman lens sensor has five beam ports, six array ports, and four dummy ports. The sensor design is optimized to work in the $\mathrm{mmW}$ band, i.e., from 27 to $29 \mathrm{GHz}$ with focus on the central frequency of $28 \mathrm{GHz}$. The response of each port of the Rotman lens sensor was considered in terms of its s-parameters. Next, the sensor was loaded with a cylindrical beaker containing aqueous solutions. The beaker was placed on the sensor. The responses of multiple ports were investigated to confirm whether a Rotman lens can be used as an alternate and viable candidate for sensing applications.

The paper is organized as follows. Section 2 describes the basic principle of a Rotman lens and the geometric design of the proposed $\mathrm{mmW}$ Rotman lens sensor. It also presents the fabricated prototype and discusses in detail the s-parameter characterization in terms of reflection and coupling coefficients and surface current distributions. Section 3 describes the preparation method of the aqueous solutions and the test of the Rotman lens as a sensor by loading it with various aqueous solutions. For proof of concept, the sensing was characterized between port numbers (P3-P9). Section 4 considers the signal processing aspect of the design in analyzing the abundant port data via the polarity correlator algorithm, which was presented in our earlier work [12].

\section{Rotman Lens}

\subsection{Structure}

The Rotman lens has been widely used as a beamforming network. The schematic design of the Rotman lens is presented in Figure 1 [13]. The design consists of two contours forming a complete cavity of parallel plates. The inner contour normally contains $\mathrm{M}$ input ports, also known as the beam ports, while the outer contour contains $\mathrm{N}$ number of ports connected via routed or simple transmission lines to $\mathrm{N}$ number of array ports. When a signal is applied, it gets transmitted and received by all the ports. A progressive phase shift that is linear in nature is observed due to the disparities in the length of electrical lines among the output ports. This behavior makes a Rotman lens a true-time delay device with varying phase fronts at the array input via providing path delays within the lens cavity [14]. This path delay procedure is independent of any frequency [15], making the lens the best choice for various wideband applications that require wide-angle frequency scanning. In the lens design, conduction and absorption losses can be reduced by further adding dummy ports. From the schematic design of Figure 1, the main variables that contribute to the design are the tri-focal points denoted by $F_{1}, F_{2}$, and $F_{3}$, and the main central focal length $f_{1}$. On-axis focal point $F_{1}$ and off-axis focal points $F_{2}$ and $F_{3}$ are located on the beam contour at angles of $0,+\alpha$, and $-\alpha$, respectively [16]. 


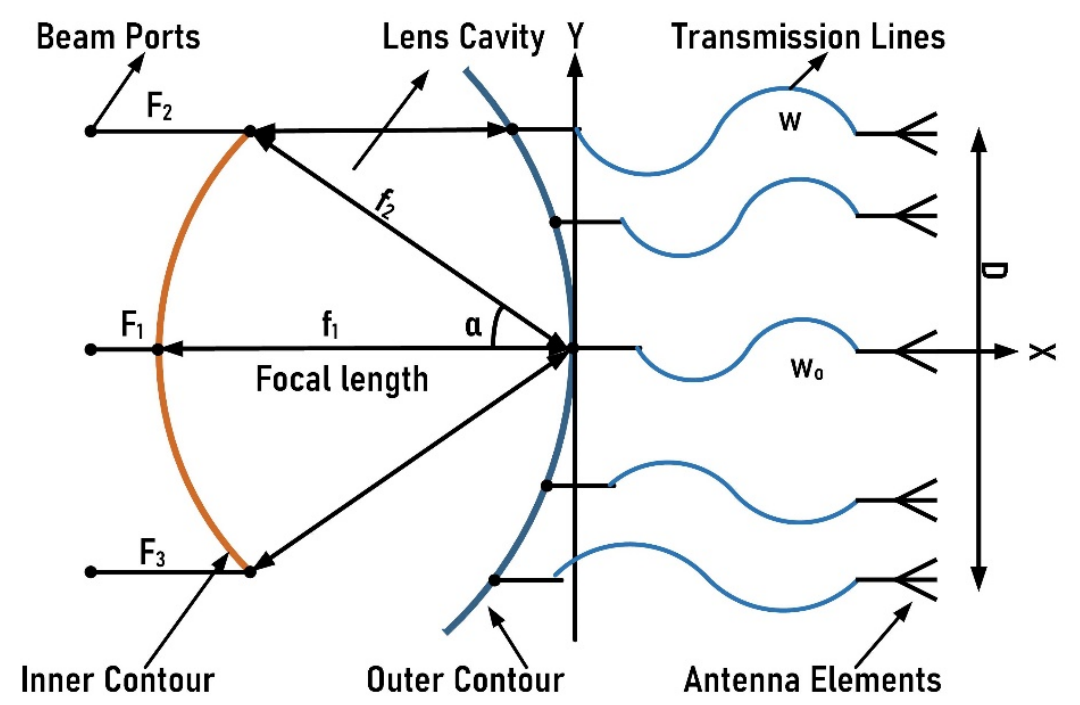

Figure 1. Basic schematic of a Rotman lens.

\subsection{Sensor Design}

The design of the proposed Rotman lens sensor is depicted in Figure 2. The design was realized on a Rogers RO4003C substrate with dielectric permittivity of 3.55, loss tangent of 0.0027 , and a thickness of $0.8 \mathrm{~mm}$. The design consists of a full ground plane on the rear side of the substrate, while the main routing transmission lines are formed on the upper side of the substrate. Multiple ports are distributed such that five beam ports are to the left side, six array ports are on the right side, and four dummy ports are designed and located on the top and bottom of the structure. The main central contour selected is in an elliptical shape for better beam propagation performance. The structure is designed to operate in the band of interest from 27 to $29 \mathrm{GHz}$ with optimal dimensions provided in Table 1 focusing on the central frequency of $28 \mathrm{GHz}$. The design parameters were obtained via a commercial tool called Rotman Lens Designer (RLD) [17].

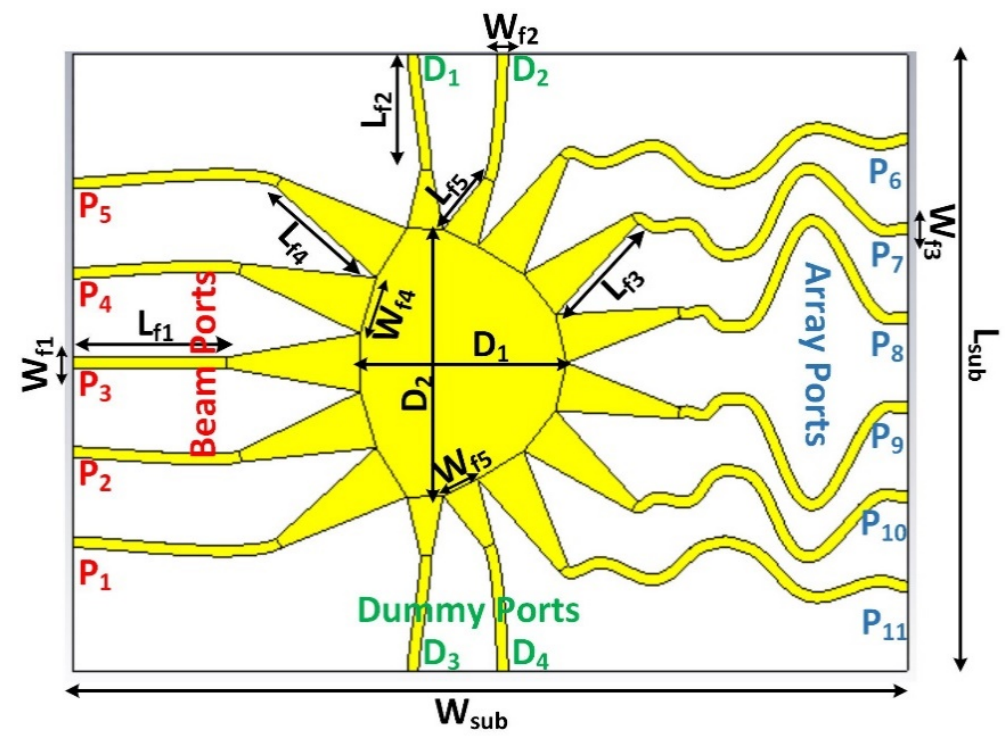

Figure 2. Geometric design of the proposed Rotman lens sensor. 
Table 1. Optimized dimensions of the proposed Rotman lens sensor operating in the mmW band.

\begin{tabular}{cccc}
\hline Parameter & Value $(\mathbf{m m})$ & Parameter & Value $(\mathbf{m m})$ \\
\hline $\mathrm{L}_{\mathrm{sub}}$ & 140 & $\mathrm{~W}_{\mathrm{sub}}$ & 103 \\
$\mathrm{~L}_{\mathrm{f} 1}$ & 35 & $\mathrm{~W}_{\mathrm{f} 1}$ & 1.85 \\
$\mathrm{~L}_{\mathrm{f} 2}$ & 20.54 & $\mathrm{~W}_{\mathrm{f} 2}$ & 1.85 \\
$\mathrm{~L}_{\mathrm{f} 3}$ & 20.66 & $\mathrm{~W}_{\mathrm{f} 3}$ & 1.85 \\
$\mathrm{~L}_{\mathrm{f} 4}$ & 22.67 & $\mathrm{~W}_{\mathrm{f} 4}$ & 9.73 \\
$\mathrm{~L}_{\mathrm{f} 5}$ & 10.16 & $\mathrm{~W}_{\mathrm{f} 5}$ & 6.48 \\
$\mathrm{D}_{1}$ & 34.9 & $\mathrm{D}_{2}$ & 45.22 \\
\hline
\end{tabular}

\subsection{S-Parameters}

The realized prototype of the proposed Rotman lens sensor is presented in Figure 3. An LPKF Protomat E33 milling and cutting machine [18] was used to fabricate the structure. A high performance computation-based simulator, commercially known as Computer Simulation Technology (CST-MWS) [19], was used to rigorously compute the s-parameter performance of the proposed sensor. The main objective was to obtain a resonance in the band of interest from 27 to $29 \mathrm{GHz}$ with central frequency being $28 \mathrm{GHz}$ for $\mathrm{mmW}$ applications. Figure 4 depicts the beam port (P1-P5) performance of the simulator results with the measured response. It can be seen from the simulation results that the whole band of interest is being covered by the sensor. The measurements fairly confirm the simulation results, and interestingly, it can be observed that multiple responses of different behavior appear within the band of interest with acceptable matching at $28 \mathrm{GHz}$. Next, the s-parameters of the array port (P6-P11) were simulated, with the results presented in Figure 5. It is evident that the simulation results confirmed with measurements cover the entire band from 27 to $29 \mathrm{GHz}$. For the coupling analysis of the beam and array ports, Figures 6 and 7 depict the simulated and measured results. It can be seen that the simulation results are well below the $-20 \mathrm{~dB}$ reference line among the ports for both cases, while the measurement results are near $-15 \mathrm{~dB}$ for the beam ports and array ports coupling with one signal near $-12 \mathrm{~dB}$ for the array port coupling at P8-P10. The amplitude shifts in both the reflection and insertion loss could be due to poor soldering of the connectors with mutual coupling strength between the transmission lines. However, the main concern here is not the frequency shifts or dips above or below the reference lines of -10 or $-20 \mathrm{~dB}$. Similarly, the transmission coefficients of the proposed design are presented in Figures 8 and 9 . Figure 8 depicts the effect on all the ports in terms of its transmission coefficients when only ports 1 and 5 are activated. Figure 9 depicts the port response when ports 6 and 11 are active. It can be seen that the proposed Rotman lens sensor has transmission curves in the range of -4 to $-15 \mathrm{~dB}$. To verify the design, only single port measurements were taken, as shown in Figures 8 and 9 for port P16 and port P113. The difference among the simulation and measurements was $-4 \mathrm{~dB}$ for both ports, i.e., P16 and P113. The core intention was to analyze the complete $\mathrm{mmW}$ band of interest by exploiting the abundant data that were generated and collected from all the ports of the proposed Rotman lens sensor. This data can then be utilized via signal processing algorithms for better characterization accuracy. 

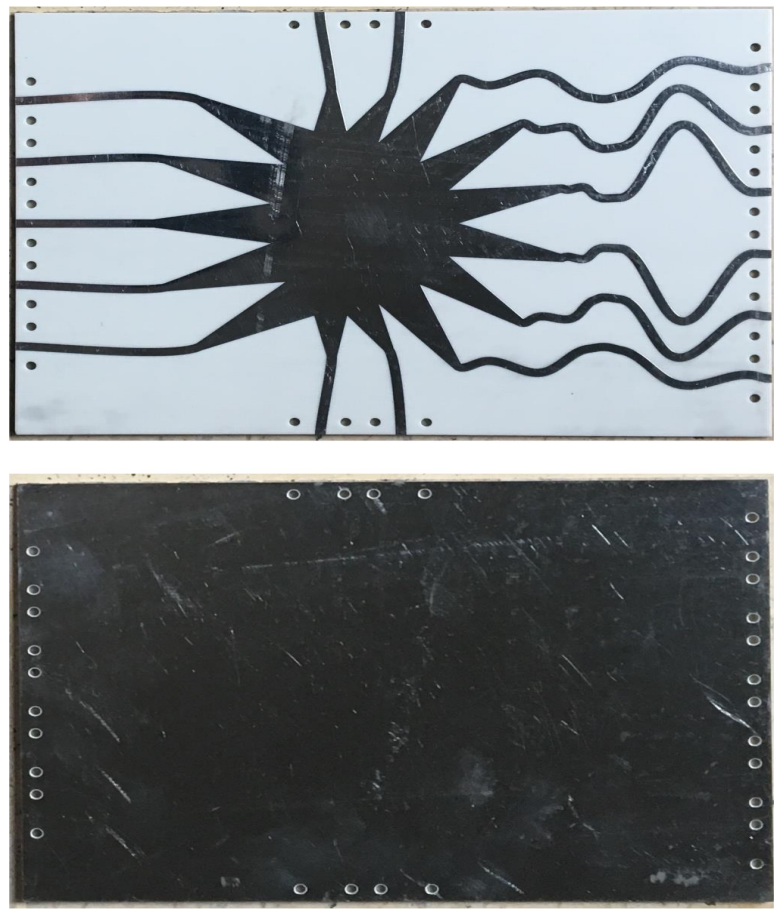

Figure 3. Realized prototype of the proposed Rotman lens sensor-front and back view.

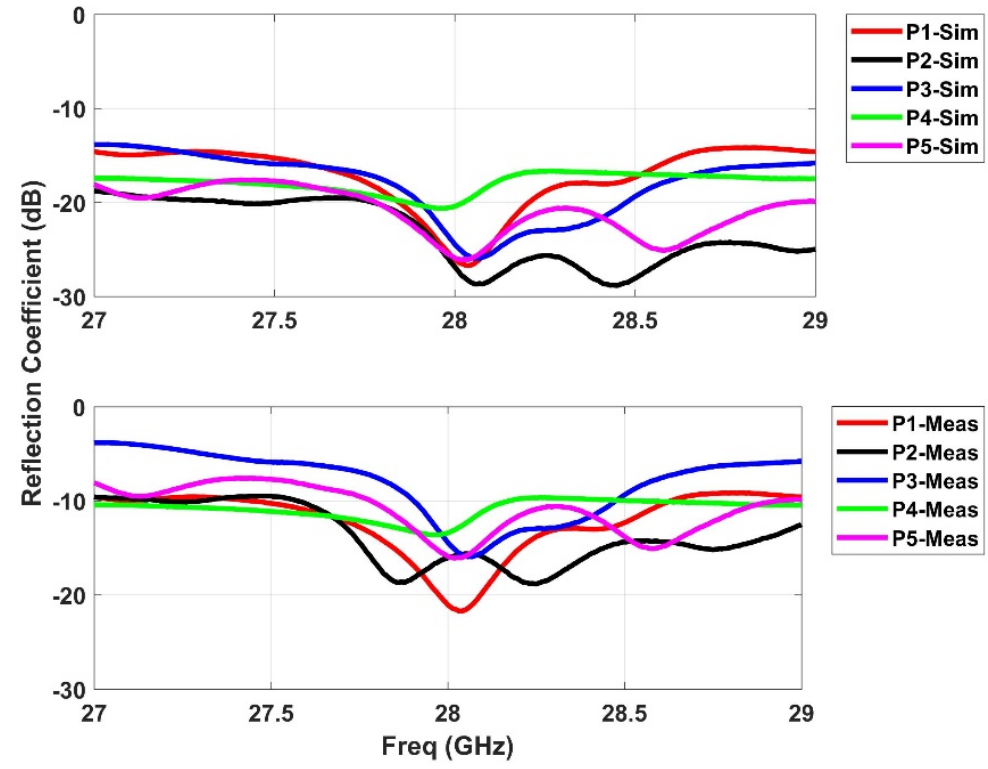

Figure 4. Simulated and measured s-parameters for the beam ports (P1-P5). 


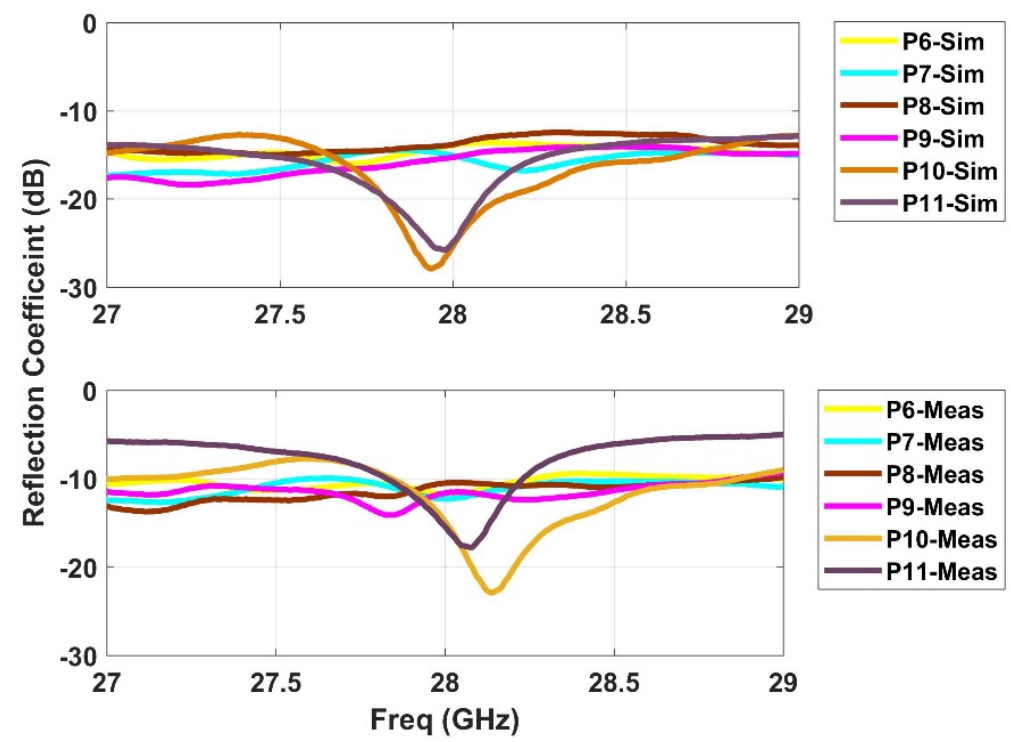

Figure 5. Simulated and measured s-parameters for the array ports (P6-P11).

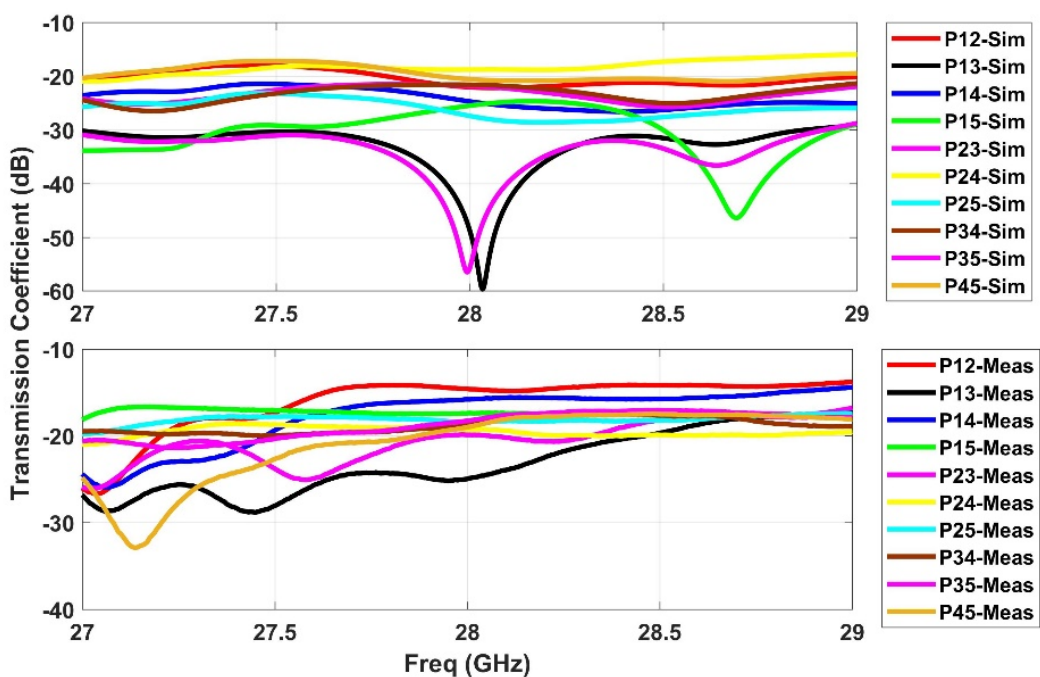

Figure 6. Simulated and measured s-parameters for the coupling among the beam ports (P1-P5).

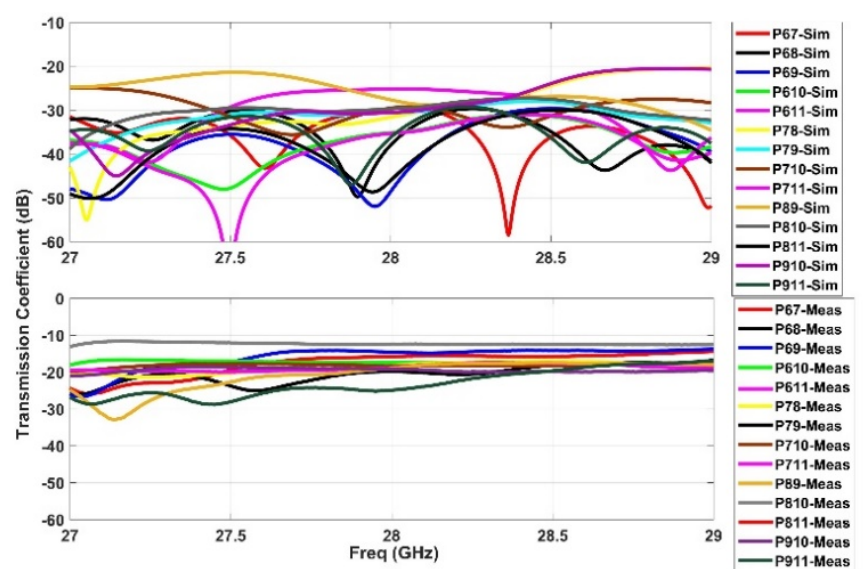

Figure 7. Simulated and measured s-parameters for the coupling among the array ports (P6-P11) 


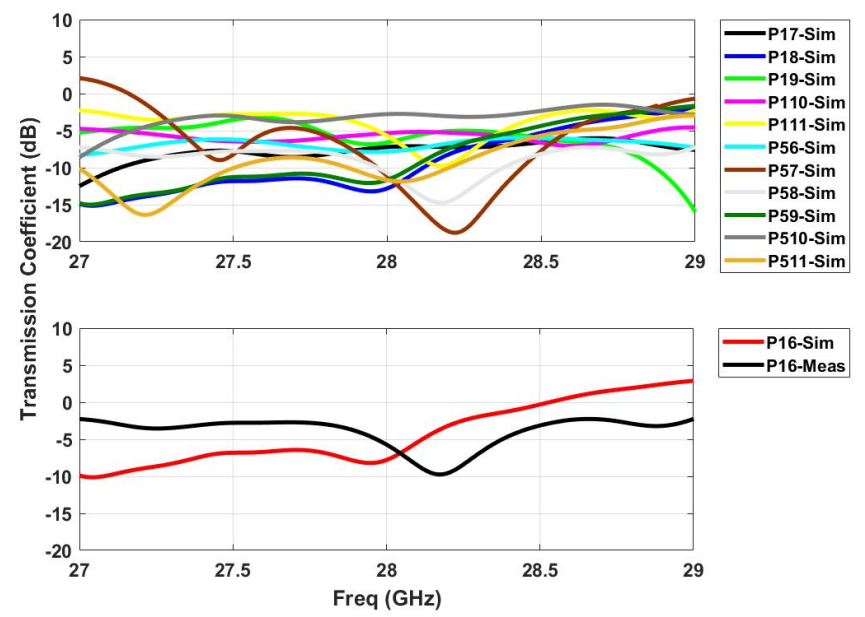

Figure 8. Simulated transmission coefficients (top) when ports 1 and 5 are active with measurement verification on a single port (P16) (bottom).

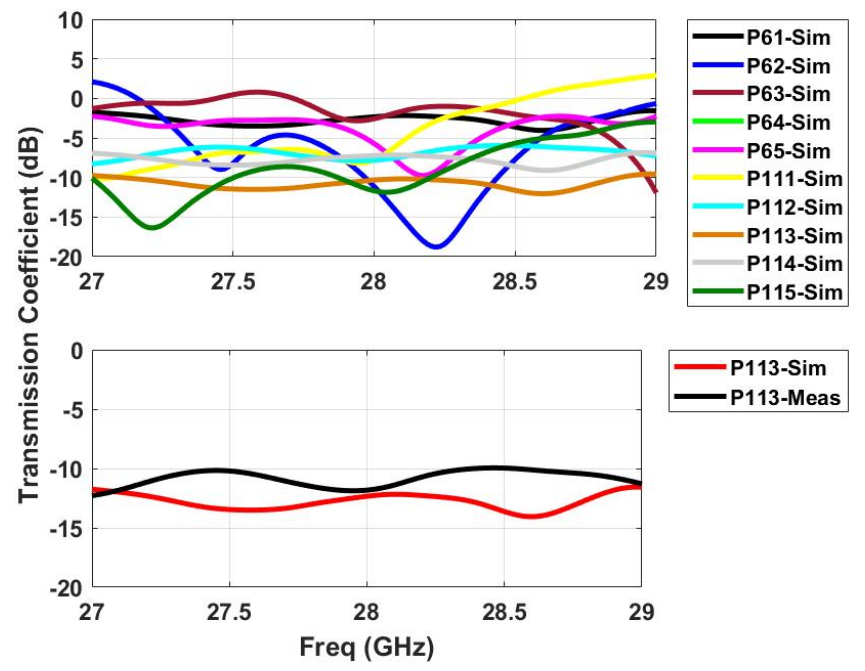

Figure 9. Simulated transmission coefficients (top) when ports 6 and 11 are active with measure-ment verification on a single port (P113) (bottom).

\subsection{Surface Current Distributions}

Figure 10a-e represents the surface current distributions of the proposed Rotman lens sensor for all the five beam ports (P1-P5). It can be seen that when each port is excited individually, the wave gets propagated from the port, follows the main elliptical contour, and reaches the corresponding array ports on the right-hand side of the substrate. For each excitation, wave energy gets transmitted and absorbed into the port in close proximity to the array ports. Similarly, Figure 11a-f depicts the surface current distributions of the array ports (P6-P11). Each array port gets excited individually, with EM energy travelling from the elliptical contour to the beam ports. A few absorptions are seen near the coupling array ports with some energy going into the dummy ports. The overall surface current distributions confirm that the proposed Rotman lens sensor properly propagates the EM wave between all the ports. 


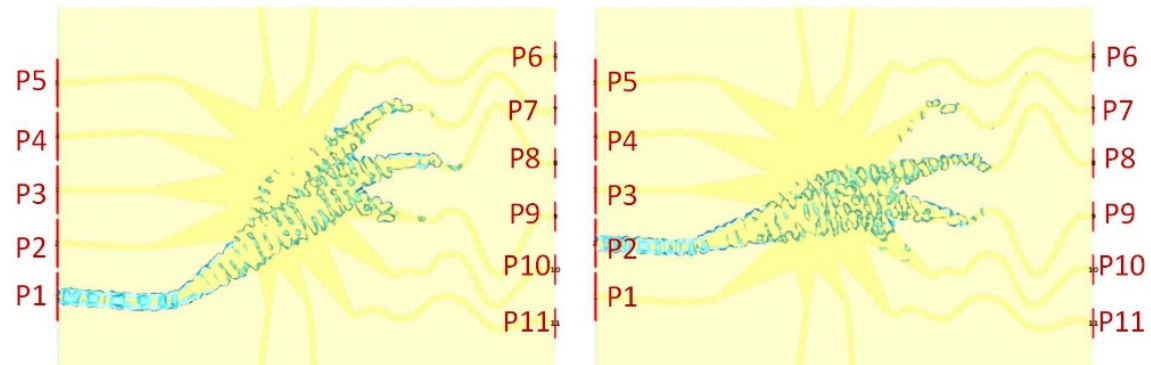

(a)

(b)
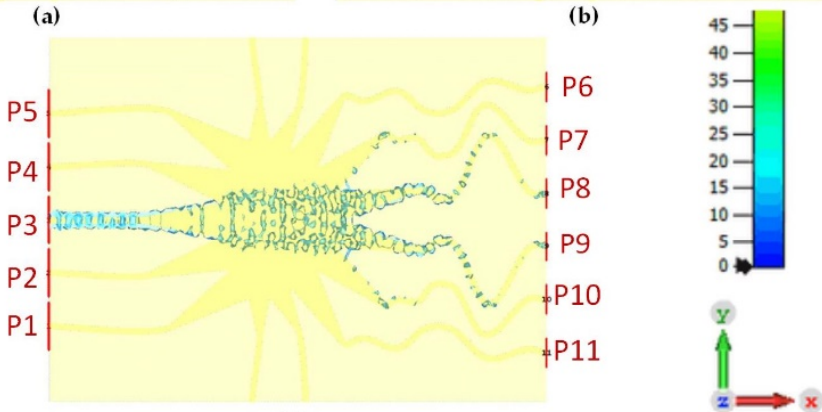

(c)

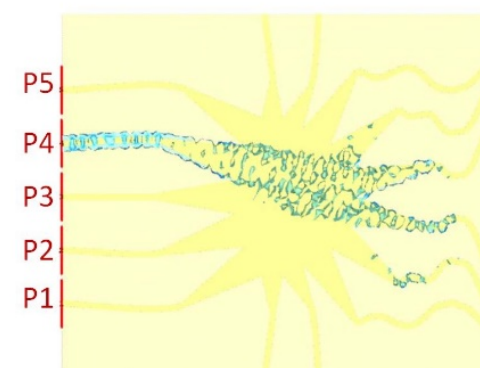

(d)

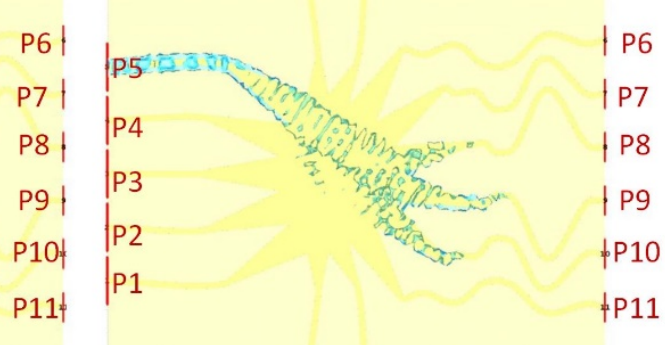

(e)

Figure 10. Surface current distributions of the beam port (P1-P5), from below to above, for the proposed Rotman lens sensor; (a) P1 is active, (b) P2 is active, (c) P3 is active, (d) P4 is active, (e) P5 is active.

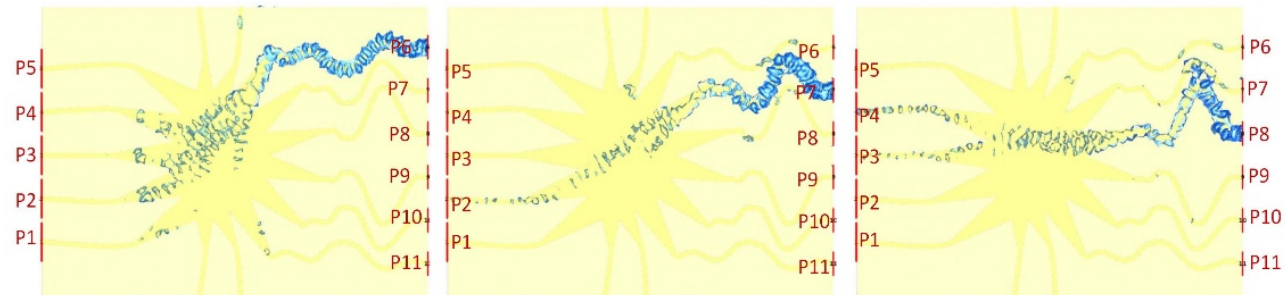

(a)

(b)

(c)

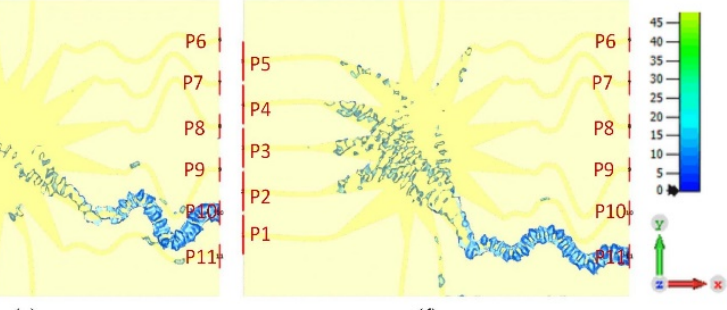

(e)

(f)

Figure 11. Surface current distributions of the array port (P6-P11), from below to above, for the proposed Rotman lens sensor; (a) P6 is active, (b) P7 is active, (c) P8 is active, (d) P9 is active, (e) P10 is active, (f) P11 is active. 


\section{Sample Load for Testing the Sensor \\ 3.1. Material Preparation}

Various in-lab solutions were prepared in order to verify that the proposed Rotman lens can work as a sensor. Aqueous glucose solution was utilized as a loading element due to its popularity in the literature [20] and ease of preparation and procurement. The concentrations selected for the experiment were of 60,100 , and $200 \mathrm{mg} / \mathrm{dL}$ as depicted in Figure 12. Dextrose anhydrous powder was used in the preparation of the aqueous solution as it is easily available and widely used in the food industry [21]. Moreover, it is an optimal powder in testing a liquid-based solution compared to fructose. Homogeneity of the proposed solutions was ensured by keeping a defined room temperature and a constant spinning speed [22]. The solutions were characterized by utilizing a SPEAG [23] dielectric testing kit (DAK).

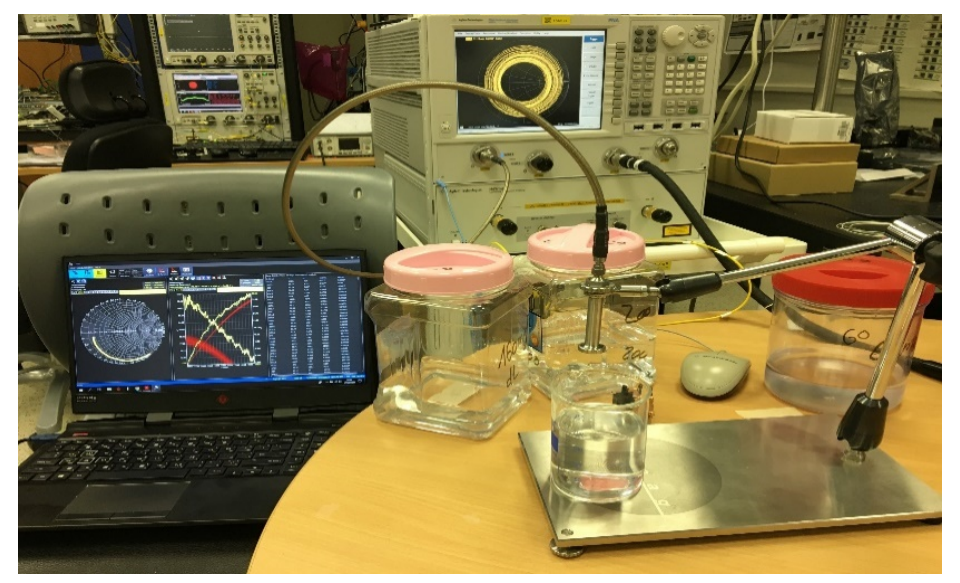

Figure 12. Solutions being tested for their material characterization via SPEAG DAK tool.

\subsection{Sensor Validation}

The proposed sensor was tested with the prepared in-lab solutions. The solutions were injected with a medical syringe inside the cylindrical beaker at appropriate height of $0.3 \mathrm{~cm}$ and room temperature of $25^{\circ} \mathrm{C}$. Figure 13a shows the beaker. Its geometric dimensions were an upper diameter of $30 \mathrm{~mm}$ and a height of $39 \mathrm{~mm}$. It was placed onto the Rotman lens, and Figure $13 \mathrm{~b}$ depicts the characterization of the realized prototype. The measurements were taken via a vector network analyzer (VNA) [24]. The placement of the liquids onto the sensor generated different signal behavior over the entire band of interest due to multiple ports as presented earlier for the s-parameter results. In order for the Rotman lens to work as a sensor, it needs to introduce variations in port responses including the presence of some nulls in the band of interest. In our analysis, we measured the different resonance behaviors of only two ports (P3-P9) for each aqueous concentration including air and solutions (60, 100 , and $200 \mathrm{mg} / \mathrm{dL}$ ). Figure 14 presents the various resonance behaviors (reflection and transmission coefficient) observed in comparison between simulated and measured results for the proposed sensor. It can be seen from Figure 14a that when the beaker was placed with air inside (no solution), the simulated response, shown by the red curve, covered the entire band of interest, i.e., from 27 to $29 \mathrm{GHz}$. The measured response of the same red curve, shown by the dotted yellow line, also covered the entire band. Similarly, when the solutions were added to the cylindrical beaker at 60 (black dotted curve), 100 (blue dotted curve), and $200 \mathrm{mg} / \mathrm{dL}$ (pink dotted curve), different resonance behaviors were observed. Specifically, the nulls of the aqueous solutions were analyzed where it was seen that the measured curves moved towards the lower end of the frequency band with an increase in the aqueous concentrations. This behavior was also observed in the transmission coefficient response of the sensor when port 3 was active, as shown in Figure 14b. When there was no solution and just air inside the beaker, the transmission coefficients were near the $-5 \mathrm{~dB}$ resonance. With the addition of solutions to the beaker, the sensor's response became weak 
as the resonance level decreased from -5 to around $-10 \mathrm{~dB}$. This decrease may be due to the coupling among the multiple ports, but still the measurements were in acceptable ranges of transmission coefficients for mmW bands. Similarly, as seen in Figure 14c,d, analysis based on the measurement for port 9 with prepared in-lab solutions reveal that the beaker with no solution (air) covered the entire band from 27 to $29 \mathrm{GHz}$ (red simulated curve), while the measured (yellow dotted curve) also covered the same band. For the solutions at 60 (black dotted curve), 100 (blue dotted curve), and $200 \mathrm{mg} / \mathrm{dL}$ (pink dotted curve), again, null shifting towards the lower end of the frequency bands was observed. Table 2 presents the null values for each of the measured ports as per loading of the aqueous solutions. In conclusion, for both the ports, a shift towards the lower end of the spectrum was observed when higher concentrations were added to the beaker. This proves that the sensor based on the Rotman lens design performs in somewhat similar manner to other available RF sensors in the literature when loaded with different materials [25]. The added advantage with this design is that abundant data could be gathered from the multiple ports as per lens geometry and can be utilized by various signal processing and artificial intelligence algorithms in providing more insight into liquid characterization.

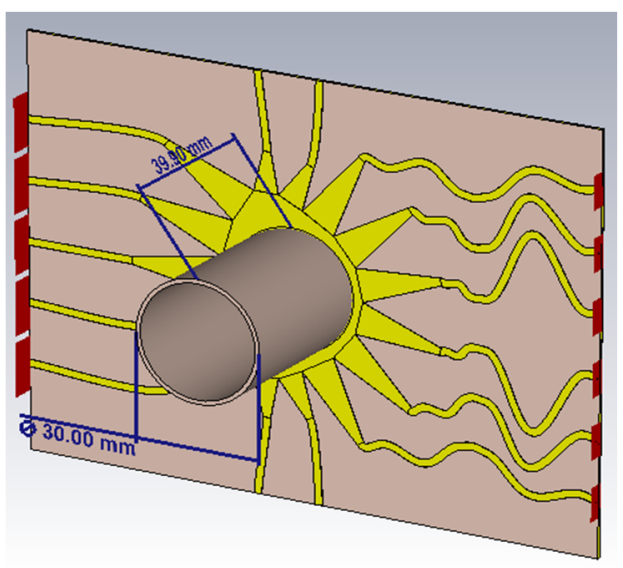

(a)

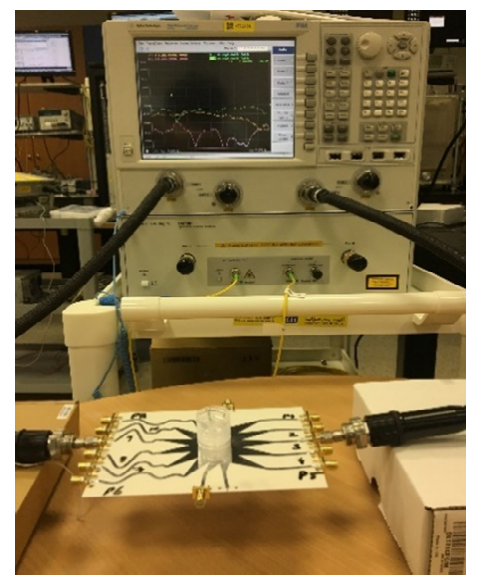

(b)

Figure 13. Testing the sensor: (a) Placement of the beaker onto the Rotman lens with the cylinder's geometrical dimensions; (b) Characterization of the proposed sensor.

Table 2. Shifting null values for ports 3 and 9 measurements based on loading Rotman lens sensor with aqueous solution.

\begin{tabular}{cccc}
\hline Aqueous Solutions & Nulls @ Port 3 & Aqueous Solutions & Nulls @ Port 9 \\
\hline Air & $28.01 \mathrm{GHz}$ & Air & $27.7 \mathrm{GHz}$ \\
$60 \mathrm{mg} / \mathrm{dL}$ & $27.96 \mathrm{GHz}$ & $60 \mathrm{mg} / \mathrm{dL}$ & $27.67 \mathrm{GHz}$ \\
$100 \mathrm{mg} / \mathrm{dL}$ & $27.91 \mathrm{GHz}$ & $100 \mathrm{mg} / \mathrm{dL}$ & $27.63 \mathrm{GHz}$ \\
$200 \mathrm{mg} / \mathrm{dL}$ & $27.77 \mathrm{GHz}$ & $200 \mathrm{mg} / \mathrm{dL}$ & $27.47 \mathrm{GHz}$ \\
\hline
\end{tabular}



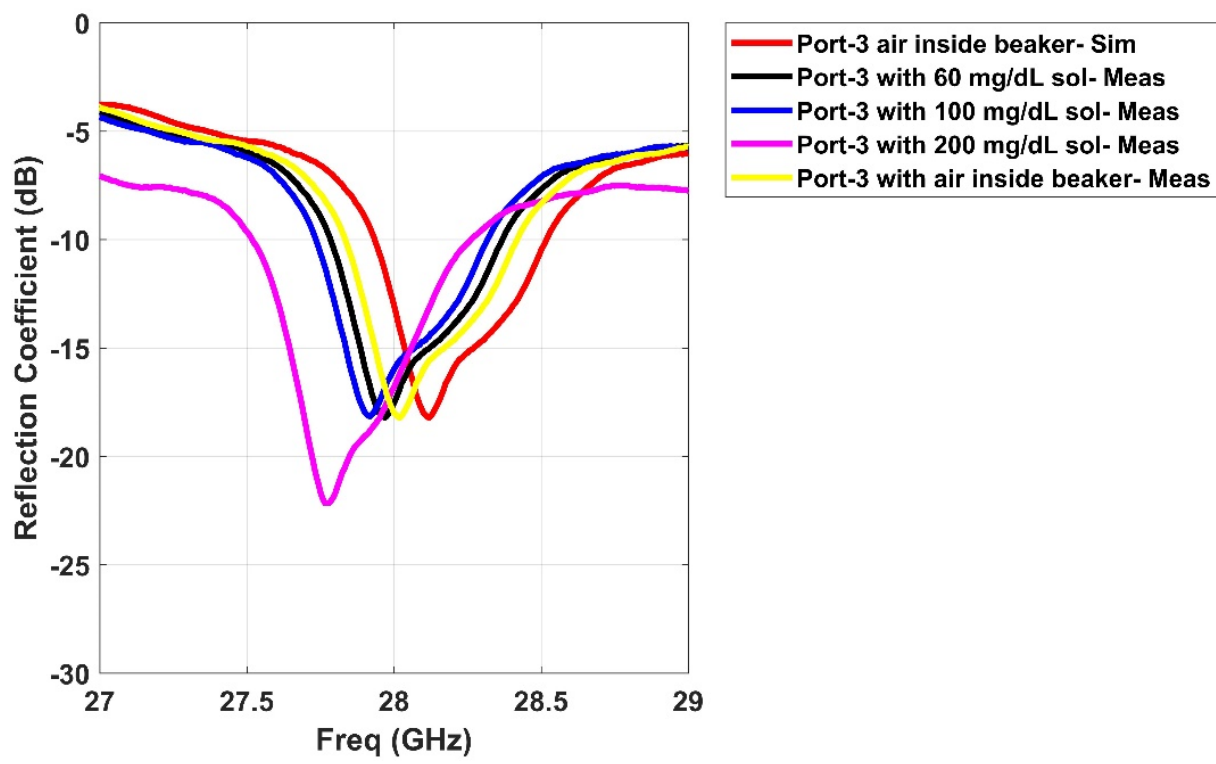

(a)
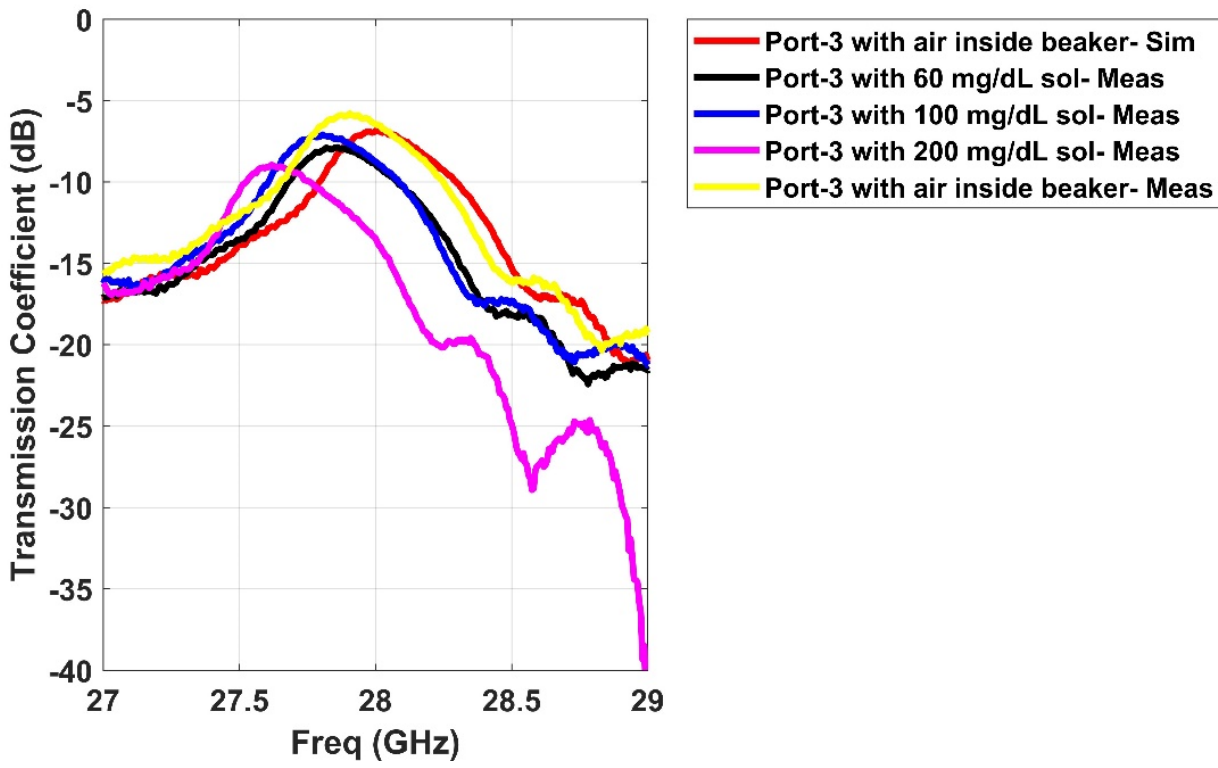

Port-3 with air inside beaker- Meas

(b)

Figure 14. Cont. 

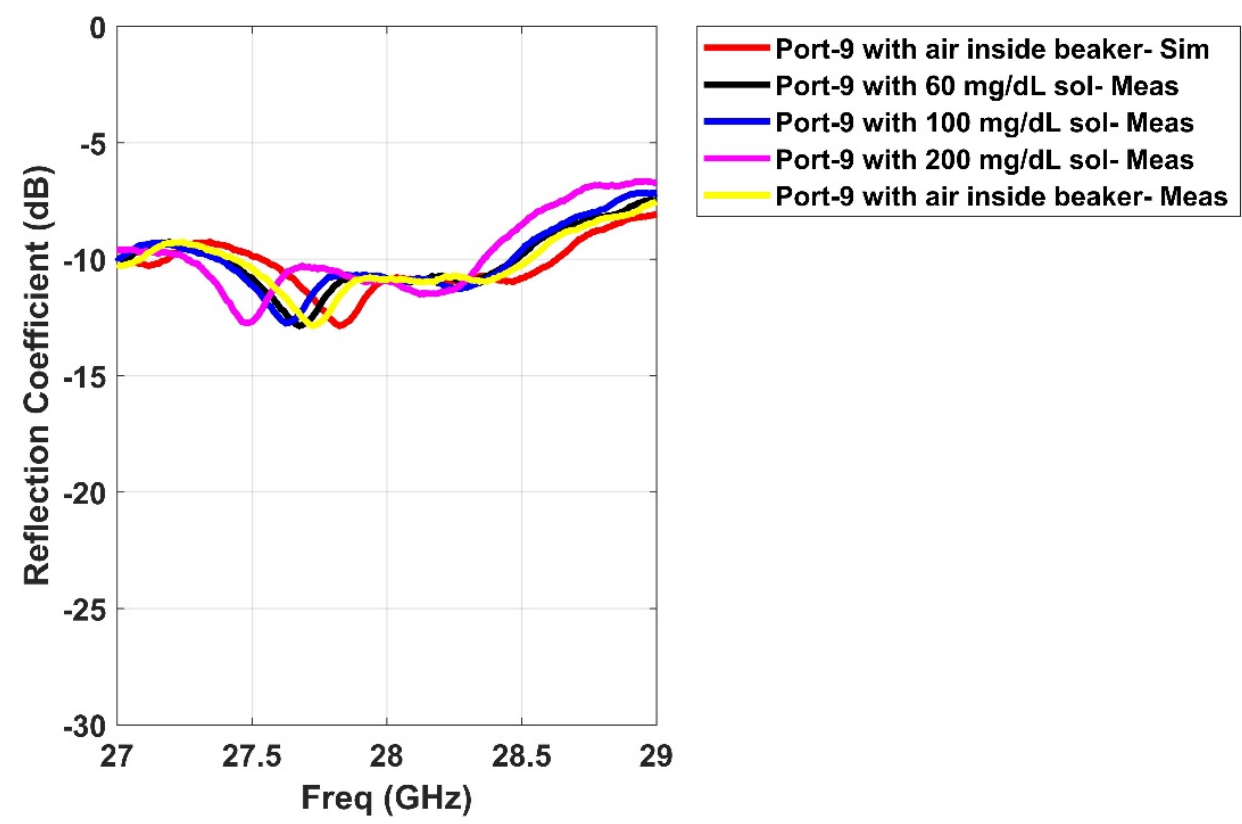

(c)
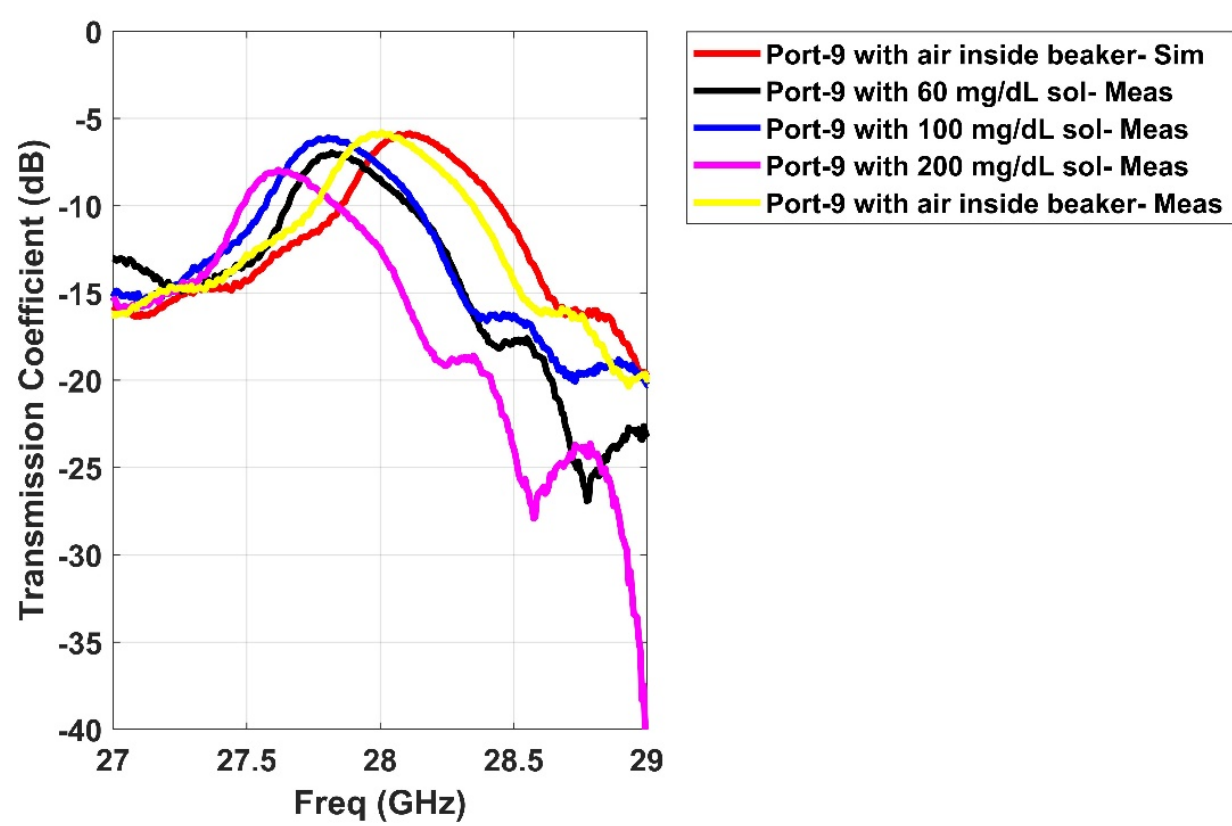

(d)

Figure 14. Comparison of simulated and measured responses of the proposed Rotman lens sensor after loading with prepared in-lab aqueous solutions: (a) Port 3 reflection coefficient; (b) Port 3 transmission coefficient between P39; (c) Port 9 reflection coefficient; (d) Port 9 transmission coeffcient between P93.

\section{Port Data Analysis}

The polarity correlator previously introduced in [12] can be used to analyze the responses of the Rotman lens when the lens works as a sensor. As discussed in [12], the polarity correlator exploits the variations present in the whole response of the sensor in order to differentiate between different concentrations by measuring the similarity of a sensor's response to an unknown concentration with pre-stored sensor responses to known concentrations. To provide comprehensive analysis for all possible Rotman lens responses, this section presents results produced only by simulation. This is because the Rotman lens 
has five beam ports and six array ports; hence, the number of possible lens responses is 66. The numbering and symbols denoting these responses at particular concentrations are listed in Table 3. For example, P5-P1 (22) means that the response between ports 5 and 1 is given the number 22. The polarity correlator works on the sign of filtered responses, as described below.

Table 3. Numbering and symbols denoting responses of the Rotman lens.

P1-P1 (1), P2-P2 (2), P3-P3 (3), P4-P4 (4), P5-P5 (5), P6-P6 (6), P7-P7 (7), P8-P8 (8), P9-P9 (9), P10-P10 (10), P11-P11 (11), P2-P1 (12), P3-P1 (13), P3-P2 (14), P4-P1 (15), P4-P2 (16), P4-P3 (17), P4-P5 (18), P4-P6 (19), P4-P7 (20), P4-P10 (21), P5-P1 (22), P5-P2 (23), P5-P3 (24), P5-P6 (25), P5-P7 (26), P5-P8 (27), P5-P9 (28), P5-P10 (29), P5-P11 (30), P6-P1 (31), P6-P2 (32), P6-P3 (33), P6-P8 (34), P6-P9 (35), P6-P10 (36), P6-P11 (37), P7-P1 (38), P7-P2 (39), P7-P3 (40), P7-P6 (41), P7-P8 (42), P8-P1 (43), P8-P2 (44), P8-P3 (45), P8-P4 (46), P8-P10 (47), P8-P11 (48), P9-P1 (49), P9-P2 (50), P9-P3 (51), P9-P4 (52), P9-P7 (53), P9-P8 (54), P9-P10 (55), P9-P11 (56), P10-P1 (57), P10-P2 (58), P10-P3 (59), P10-P7 (60), P10-P11 (61), P11-P1 (62), P11-P2 (63), P11-P3 (64), P11-P4 (65), P11-P7 (66)

Let $s_{i}^{m}(k \Delta f)$ denote the $i$ th response $(i=1,2, \ldots, 66)$ corresponding to a solution of concentration $m$. The symbol $k$ denotes the $k$ th response sample, and $\Delta f$ is the sampling interval in the frequency domain. The pulse fidelity factor is used here to differentiate between pre-processed output responses of two different concentrations $m$ and $n$. The pre-processed response $r_{i}^{m}(k \Delta f)$ is obtained as follows:

$$
r_{i}^{m}(k \Delta f)=\operatorname{sign}\left(s_{i}^{m}(k \Delta f)-s_{i}^{m}((k-1) \Delta f)\right)
$$

where $\operatorname{sign}(x)=1$ if $x>0$ and -1 if $x<0$. This pre-processing step improves the discrimination between the different concentrations, as previously demonstrated in [12]. The pulse fidelity factor $p_{i}^{m n}$ is given by:

$$
p_{i}^{m n}=\max _{k_{0}} \frac{\sum_{k} r_{i}^{m}(k \Delta f) r_{i}^{n}\left(\left(k-k_{0}\right) \Delta f\right)}{\sqrt{\sum_{k}\left|r_{i}^{m}(k \Delta f)\right|^{2} \sum_{k}\left|r_{i}^{n}(k \Delta f)\right|^{2}}} .
$$

The polarity correlator implements both operations of Equations (1) and (2). In our development, the pulse fidelity factor is used to measure the similarity between two preprocessed responses produced by the Rotman lens at three different glucose concentrations $(m, n=1,2,3)$. These concentrations are produced by pure water $(m=n=1)$, and water with glucose concentrations of $60(m=n=2)$ and $100 \mathrm{mg} / \mathrm{dL}(m=n=3)$. Note that for better discrimination, the fidelity factor $p_{i}^{m n}$ between the responses of two different concentrations $(m \neq n)$ should be as small a value as possible (i.e., close to zero). For $m=n$, the fidelity factor is identically 1 .

Figure 15 shows the maximum value of fidelity factor, denoted by $\zeta(i)$, of the $i$ th response computed for $m, n=1,2,3(m \neq n)$. That is,

$$
\zeta(i)=\max \left\{p_{i}^{12}, p_{i}^{13}, p_{i}^{23}\right\}, i=1,2,3, \ldots, 66 .
$$




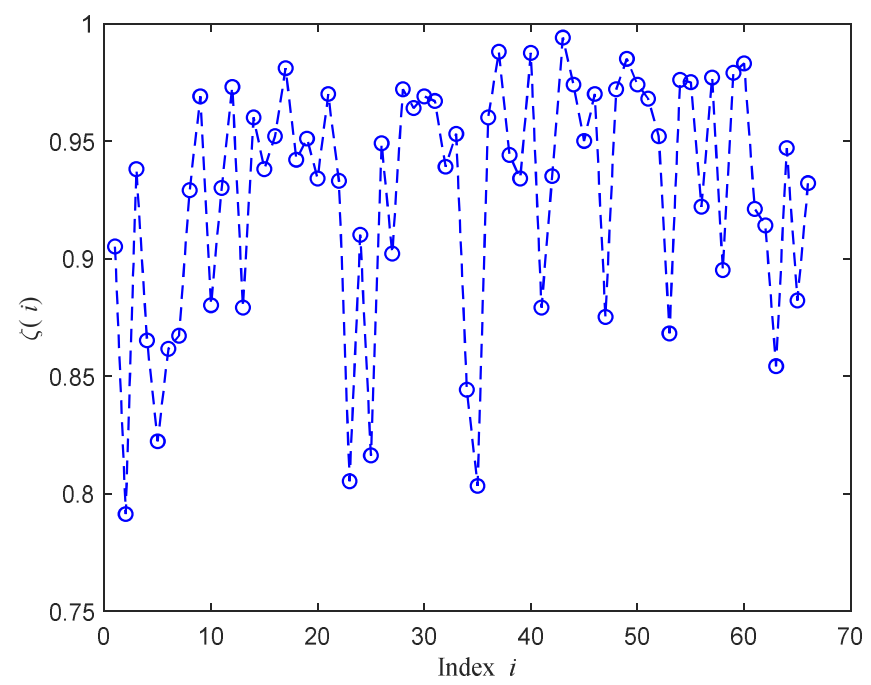

Figure 15. The maximum of fidelity factor versus the response index $i$.

It is observed from the figure that the fidelity factor varies among responses of different ports. Ports that have lower values of $\zeta(i)$ are highly preferred to differentiate between given concentrations. Figure 16 shows the number of responses that have values of $\zeta(i)$ less than or equal to a given threshold, $T$. Table 4 gives the number of responses, the $\zeta(i)$ of which represents values less than or equal to $T=0.75,0.8,0.85,0.9,0.95$, and 1 . For example, six different responses have maximum fidelity factor with values less than or equal to 0.85 . These responses corresponding to the index $i=2,5,23,25,34$, and 35 are obtained from ports P2-P2, P5-P5, P5-P2, P5-P6, P6-P8, and P6-P9, with Figure 17 showing their $\zeta(i)$ versus the response index $i$. Therefore, we can consider the determination of a concentration value as a classification problem, along the lines of the approach reported in [12], but with additional steps exploiting data of more than one port of the Rotman lens. Specifically, the following steps were performed.

- Pre-measured responses of $N$ solutions with different concentration values were stored in a library. Note that each solution has six responses corresponding to $i=2,5$, $23,25,34$, and 35 .

- The fidelity factor between the response of a solution of unknown concentration and the $6 \mathrm{~N}$ responses of $\mathrm{N}$ pre-stored solutions were computed.

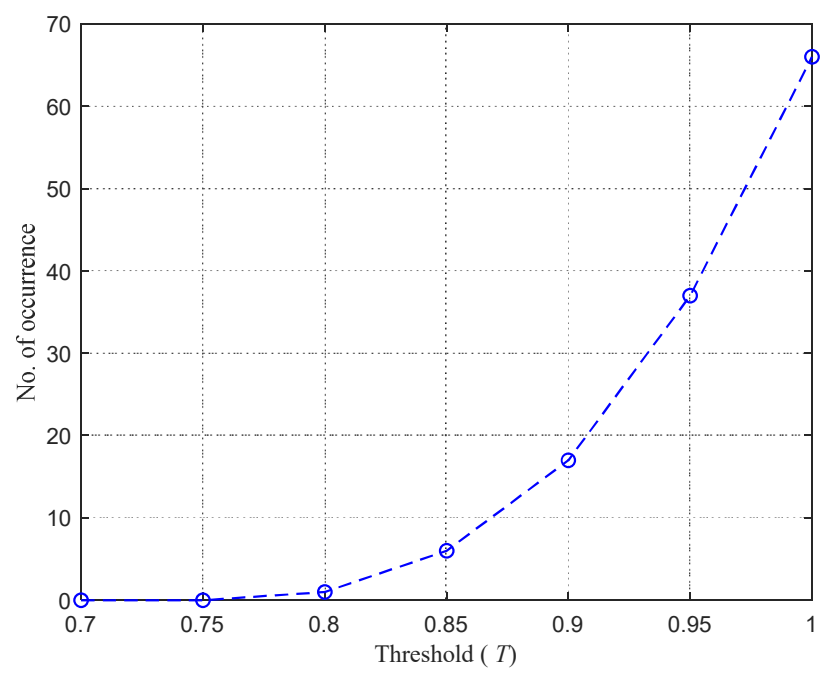

Figure 16. Number of responses that have maximum fidelity factor less than or equal to the given threshold $T$. 
Table 4. Number of responses with maximum fidelity factor less than or equal to the threshold $T$.

\begin{tabular}{cccccccccc}
\hline Threshold $(T)$ & 0.75 & 0.8 & 0.85 & & & 0.9 & & 0.95 & 1 \\
\hline Number of responses & 0 & 1 & 6 & 17 & 37 & 66 & & \\
\hline
\end{tabular}

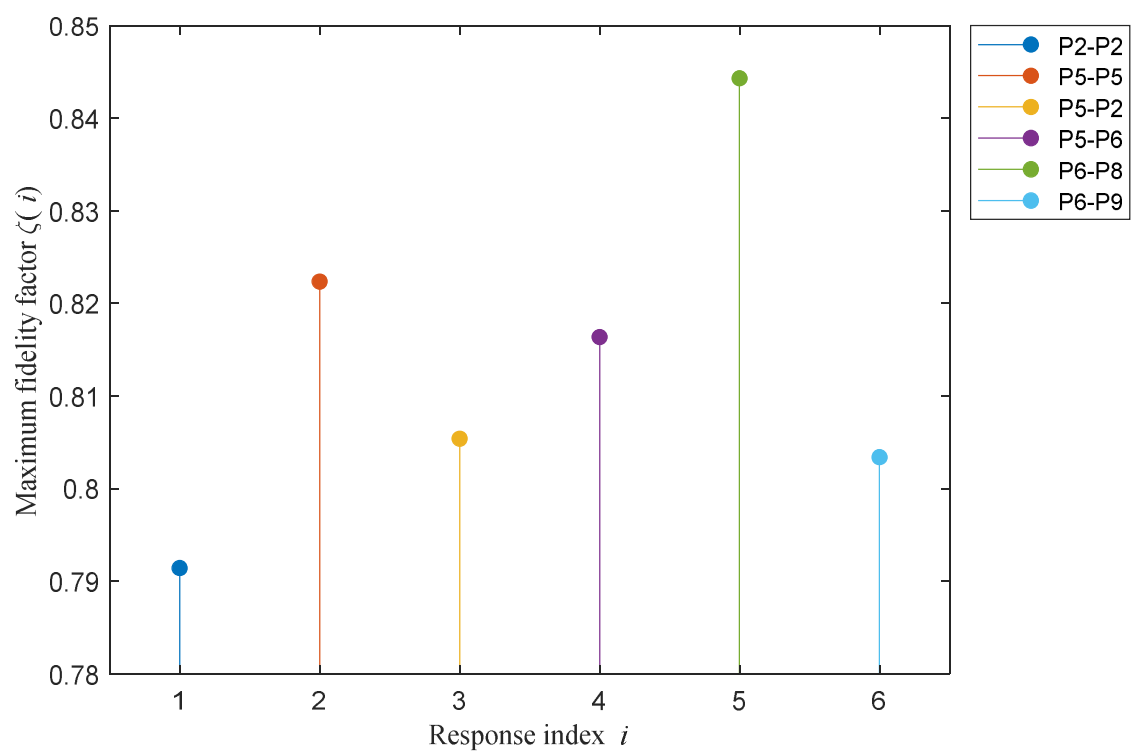

Figure 17. Responses that have maximum fidelity factor less than or equal to 0.85 .

The concentration of pre-stored response, the fidelity factor of which with the response to unknown solution is the maximum, is considered the unknown concentration of the solution under measurement. Note that the use of the Rotman lens increased the reliability of concentration determination as the number of responses with which the unknown response was cross-correlated increased sixfold. For more accurate results, more responses of the Rotman lens can be seen in Table 4 . For $T=0.9$, there are 17 responses, which can be exploited in determining the unknown concentration.

\section{Conclusions}

In this effort, and for the first time, we investigated the performance of a Rotman lens as a sensor. The proposed sensor operates in the $\mathrm{mmW}$ band with a center frequency of $28 \mathrm{GHz}$. The Rotman lens sensor consists of five beam ports, six array ports, and four dummy ports. Each port was analyzed in terms of its s-parameters and mutual coupling. A cylindrical beaker can be placed as a loading element in the central elliptical position of the Rotman lens sensor. Three in-lab aqueous solutions were prepared. Simulated and measured responses of the Rotman lens ports were analyzed and compared in terms of s-parameters. It was demonstrated that the use of the Rotman lens increases the reliability of determining the unknown concentration of a given solution by exploiting data of more than one port and through the use of a polarity correlator.

Author Contributions: Conceptualization, W.T.S., A.B.I., K.I. and S.A.A.; methodology, W.T.S., K.I., A.B.I. and S.A.A.; software, W.T.S. and A.B.I.; validation, W.T.S. and S.A.A.; formal analysis, A.B.I. and S.A.A.; investigation, W.T.S. and K.I.; resources, S.A.A.; data curation, W.T.S. and A.B.I.; writingoriginal draft preparation, W.T.S.; writing-review and editing, W.T.S. and S.A.A.; visualization, W.T.S.; supervision, S.A.A.; project administration, S.A.A.; funding acquisition, S.A.A. All authors have read and agreed to the published version of the manuscript.

Funding: This work was supported by the Researchers Supporting Project number RSP-2020/46, King Saud University, Riyadh, Saudi Arabia.

Institutional Review Board Statement: Not applicable. 
Informed Consent Statement: Not applicable.

Data Availability Statement: Data available on request from the authors.

Conflicts of Interest: The authors declare no conflict of interest.

\section{References}

1. Tiefenthaler. K.; Walter. L. Optical Sensor for Selective Detection of Substances and/or for the Detection of Refractive Index Changes in Gaseous, Liquid, Solid and Porous Samples. U.S. Patent 4,815,843, 28 March 1989.

2. Rodriguez, A.G.; Arias, D.N.P.; Gonzalez, S.B.E.; Sandoval, G.O.O.; Giraldo, O.O.H.; Trujillo, R.C.J.; Miriam Andrea Wilches Torres, M.A.W.; Cuautle, J.D.J.A.F. Sugar Concentration Measurement System Using Radiofrequency Sensor. Sensors 2019, 19, 2354. [CrossRef] [PubMed]

3. Shah, S.A.; Fioranelli, F. RF Sensing Technologies for Assisted Daily Living in Healthcare: A Comprehensive Review. IEEE Aerosp. Electron. Syst. Mag. 2019, 34, 26-44. [CrossRef]

4. Narayanan, J.S.; Gymama, S. Towards a dual in-line electrochemical biosensor for the determination of glucose and hydrogen peroxide. Bioelectrochemistry 2019, 128, 56-65. [CrossRef] [PubMed]

5. Yuen, J.D.; Baingane, A.; Hasan, Q.; Shriver-Lake, L.C.; Walper, S.A.; Zabetakis, D.; Breger, J.C.; Stenger, D.A.; Slaughter, G. A Fully-Flexible Solution-Processed Autonomous Glucose Indicator. Sci. Rep. 2019, 9, 1-9. [CrossRef] [PubMed]

6. Hasan, M.D.; Gymama, S. Hybrid Glucose/O2Biofuel Cell Based on as Pyroquinoline Quinone Glucose Dehydrogenase at the Bioanode. In Proceedings of the 2018 IEEE SENSORS, New Delhi, India, 28-31 October 2018.

7. Singh, R.; Gehlot, A.; Gupta, L.R.; Singh, B.; Tyagi, P. 7 Play with Digital Sensors. In Getting Started for Internet of Things with Launch Pad and ESP8266; River Publishers: Gistrup, Denmark, 2020; pp. 45-64.

8. Rotman, W.; Turner, R. Wide-angle microwave lens for line source applications. IEEE Trans. Antennas Propag. 1963, 11, 623-632. [CrossRef]

9. Iannacci, J.; Resta, G.; Bagolini, A.; Giacomozzi, F.; Bochkova, E.; Savin, E.A.; Kirtaev, R.; Tsarkov, A.; Donelli, M. RF-MEMS Monolithic K and Ka Band Multi-State Phase Shifters as Building Blocks for 5G and Internet of Things (IoT) Applications. Sensors 2020, 20, 2612. [CrossRef] [PubMed]

10. Mujammami, E.H.; Islam, A.; Abdelrazik, B.S. Optimum wideband high gain analog beamforming network for $5 \mathrm{G}$ applications. IEEE Access 2019, 7, 52226-52237. [CrossRef]

11. Heino, M.; Icheln, C.; Haarla, J.; Haneda, K. PCB-Based Design of a Beamsteerable Array with High-Gain Antennas and a Rotman Lens at $28 \mathrm{GHz}$. IEEE Antennas Wirel. Propag. Lett. 2020, 19, 1754-1758. [CrossRef]

12. Sethi, W.T.; Ibrahim, A.; Khaled, I.; Albishi, A.M.; Alshebeili, S.A. A New Approach to Determining Liquid Concentration Using Multiband Annular Ring Microwave Sensor and Polarity Correlator. Electronics 2020, 9, 1616. [CrossRef]

13. Vaziri, S.M.R.; Amir, R.A. An improved method of designing optimum microstrip Rotman lens based on 2D-FDTD. Int. J. RF Microw. Comput. Aided Eng. 2020, 30, e22030. [CrossRef]

14. Lu, H.; Liu, Z.; Liu, J.; Wu, G.; Liu, Y.; Lv, X. Fully Metallic Anisotropic Lens Crossover-in-Antenna Based on Parallel Plate Waveguide Loaded with Uniform Posts. IEEE Trans. Antennas Propag. 2020, 68, 5061-5070. [CrossRef]

15. Xie, Z.; Fan, C.; Zhu, J.; Huang, X. Robust beamforming for wideband array based on spectrum subspaces. IET Radar Sonar Navig. 2020, 14, 1319-1327. [CrossRef]

16. Donelli, M.; Mohammedhusen, H.M. Design and Analysis of Antenna Feeding Networks Based on the Rotman Lens Using Interval Analysis (IA). Int. J. Antennas Propag. 2020. [CrossRef]

17. Rotman Lens Designer Tool, Remcom. Available online: https://www.remcom.com/xf-rotman-lens-designer/ (accessed on 2 March 2020).

18. LPKF E33 Prototyping and Etching Machine. Available online: https://www.lpkfusa.com/products/pcb_prototyp-ing/ machines/protomat_e33/ (accessed on 25 July 2020).

19. Computer Simulation Technology Version 2019. Available online: https://www.3ds.com/products-services/sim-ulia/products/ cst-studio-suite/ (accessed on 10 June 2020).

20. Vashist, S.; Luong, J.H. Non-invasive analytics for point-of-care testing of glucose. In Point-of-Care Glucose Detection for Diabetic Monitoring and Management; CRC Press: Boca Raton, FL, USA, 2017; pp. 59-84.

21. Loba Chemie: Laboratory Chemicals, Laboratory Reagents, Dextrose Organic Reagents. 2018. Available online: https://www. lobachemie.com/Carbohydrates-03169/DEXTROSE-ANHYDROUS-CASNO-50-99-7.aspx?search=dextrose (accessed on 11 August 2020).

22. RCT Basic. IKA. 2018. Available online: https://www.ika.com (accessed on 11 August 2020).

23. Dielectric Assessment Kit from Speag. Available online: https://www.speag.com/products/dak/dielectricmeasurements/ (accessed on 15 August 2020).

24. Microwave Network Analyzer N5227A. Available online: https://www.keysight.com/en/pdx-x201878-pn-N5227A/pnamicrowave-network-analyzer-67-ghz?cc=PK\&lc=eng (accessed on 25 May 2020).

25. Ren, A.; Zahid, A.; Fan, D.; Yang, X.; Imran, M.A.; Alomainy, A.; Abbasi, Q.H. State-of-the-art in terahertz sensing for food and water security-A comprehensive review. Trends Food Sci. Technol. 2019, 85, 241-251. [CrossRef] 